\title{
Characterization of the anaerobic propionate- degrading syntrophs Smithella propionica gen. nov., sp. nov. and Syntrophobacter wolinii
}

\author{
Yitai Liu, ${ }^{1}$ David L. Balkwill, ${ }^{2}$ Henry C. Aldrich, ${ }^{3}$ Gwendolyn R. Drake ${ }^{2}$ \\ and David R. Boone'
}

Author for correspondence: David R. Boone. Tel: +1 503725 3865. Fax: +1 5037253888 .
e-mail: booned $@$ pdx.edu

1 Department of

Environmental Biology, Portland State University, PO Box 751, Portland, OR 97207-0751, USA

2 Department of Biological Science, Florida State University, Tallahassee, FL, USA

3 Department of Microbiology and Cell Science, University of Florida, Gainesville, FL, USA

\begin{abstract}
A strain of anaerobic, syntrophic, propionate-oxidizing bacteria, strain LYPT (= OCM 661' ${ }^{\top} \mathrm{T}=$ type strain), was isolated and proposed as representative of a new genus and new species, Smithella propionica gen. nov., sp. nov. The strain was enriched from an anaerobic digestor and isolated. Initial isolation was as a monoxenic propionate-degrading co-culture containing Methanospirillum hungateii JF-1 ${ }^{\top}$ as an $\mathrm{H}_{2}$ - and formate-using partner. Later, an axenic culture was obtained by using crotonate as the catabolic substrate. The previously described propionate-degrading syntrophs of the genus Syntrophobacter also grow in co-culture with methanogens such as Methanospirillum hungateii, forming acetate, $\mathrm{CO}_{2}$ and methane from propionate. However, Smithella propionica differs by producing less methane and more acetate; in addition, it forms small amounts of butyrate. Smithella propionica and Syntrophobacter wolinii grew within similar ranges of $\mathrm{pH}$, temperature and salinity, but they differed significantly in substrate ranges and catabolic products. Unlike Syntrophobacter wolinii, Smithella propionica grew axenically on crotonate, although very slowly. Co-cultures of Smithella propionica grew on propionate, and grew slowly on crotonate or butyrate. Syntrophobacter wolinii and Syntrophobacter pfennigii grow on propionate plus sulfate, whereas Smithella propionica did not. Comparisons of 165 rDNA genes indicated that Smithella propionica is most closely related to Syntrophus, and is more distantly related to Syntrophobacter.
\end{abstract}

Keywords: Smithella propionica, propionate-oxidizing bacteria, anaerobic digestor

\section{INTRODUCTION}

Propionate is an important intermediate in methanogenic fermentation: it is the precursor of a large fraction of methane from anaerobic digestors (Boone, 1982, 1984; Kaspar \& Wuhrmann, 1978a), and its accumulation inhibits anaerobic digestion (Kaspar \& Wuhrmann, 1978b). Propionate is oxidized to acetate and $\mathrm{CO}_{2}$ (Boone, 1984; Stadtman \& Barker, 1951), with the electrons generated from this oxidation ultimately transferred to methanogens that form methane by $\mathrm{CO}_{2}$ reduction. $\mathrm{H}_{2}$ (Boone \& Bryant, 1980; Wolin, 1982) and formate (Boone et al., 1989; Stams \& Dong, 1995; Thiele et al., 1988) are the interspecies

The GenBank accession number for the 165 rRNA sequence of strain LYPT is AF126282. electron carriers for this transfer. Propionate oxidation with $\mathrm{H}_{2}$ and formate production as the electron sink is exergonic only when $\mathrm{H}_{2}$ and formate concentrations are very low (Boone \& Bryant, 1980; McInerney \& Bryant, 1981; Schink, 1997) (Table 1, equation A).

The propionate-degrading bacterium Syntrophobacter wolinii was first isolated in co-cultures in which one or both of these catabolic products were continuously removed by methanogens or sulfate-reducing bacteria (Boone \& Bryant, 1980). More recently, Syntrophobacter wolinii was shown to be phylogenetically related to sulfate-reducing bacteria (Harmsen et al., 1993). This led to the demonstration that Syntrophobacter wolinii can grow slowly on propionate with sulfate as electron acceptor, and allowed the first isolation of this bacterium in axenic culture (Wallrabenstein et al., 1994). Stams et al. (1993) showed that propionate 
Table 1. Possible catabolic reactions during the anaerobic degradation of propionate

\begin{tabular}{|c|c|c|c|c|}
\hline \multirow[t]{2}{*}{ Reaction } & \multirow[t]{2}{*}{ Equation } & \multirow{2}{*}{$\begin{array}{c}\Delta \boldsymbol{G}^{\mathbf{v}} \\
(\mathbf{k J} / \text { reaction }) \dagger\end{array}$} & \multicolumn{2}{|c|}{$\mathrm{H}_{2}$ at equilibrium* } \\
\hline & & & $\mathbf{P a}$ & nM \\
\hline \multicolumn{5}{|c|}{ I. Hydrogen-producing reactions } \\
\hline A & $\mathrm{CH}_{3} \mathrm{CH}_{2} \mathrm{COO}^{-}+2 \mathrm{H}_{2} \mathrm{O} \rightarrow \mathrm{CH}_{3} \mathrm{COO}^{-}+\mathrm{CO}_{2}+3 \mathrm{H}_{2}$ & $71 \cdot 7$ & $12 \cdot 1$ & $89 \cdot 2$ \\
\hline B & $\mathrm{CH}_{3} \mathrm{CH}_{2} \mathrm{CH}_{2} \mathrm{COO}^{-}+2 \mathrm{H}_{2} \mathrm{O} \rightarrow 2 \mathrm{CH}_{3} \mathrm{COO}^{-}+\mathrm{H}^{+}+2 \mathrm{H}_{2}$ & $48 \cdot 3$ & 275 & 2024 \\
\hline \multicolumn{5}{|c|}{ II. Hydrogen-consuming reactions } \\
\hline $\mathrm{C}$ & $\mathrm{CO}_{2}+4 \mathrm{H}_{2} \rightarrow \mathrm{CH}_{4}+2 \mathrm{H}_{2} \mathrm{O}$ & $-130 \cdot 7$ & 0.317 & $2 \cdot 33$ \\
\hline $\mathrm{D}$ & $\mathrm{CH}_{3} \mathrm{CH}_{2} \mathrm{COO}^{-}+\mathrm{CO}_{2}+3 \mathrm{H}_{2} \rightarrow \mathrm{CH}_{3} \mathrm{CH}_{2} \mathrm{CH}_{2} \mathrm{COO}^{-}+2 \mathrm{H}_{2} \mathrm{O}$ & $-71 \cdot 5$ & $12 \cdot 3$ & $90 \cdot 6$ \\
\hline $\mathrm{E}(\mathrm{D}+\mathrm{B})$ & $\mathrm{CH}_{3} \mathrm{CH}_{2} \mathrm{COO}^{-}+\mathrm{CO}_{2}^{-}+\mathrm{H}_{2} \rightarrow 2 \mathrm{CH}_{3} \mathrm{COO}^{-}+\mathrm{H}^{+}$ & $-23 \cdot 3$ & 0.025 & $0 \cdot 18$ \\
\hline \multicolumn{5}{|c|}{ III. Combined hydrogen-producing and hydrogen-consuming reactions } \\
\hline $\mathrm{F}(\mathrm{B}+1 / 2 \mathrm{C})$ & $\begin{array}{l}\mathrm{CH}_{3} \mathrm{CH}_{2} \mathrm{CH}_{2} \mathrm{COO}^{-}+1 / 2 \mathrm{CO}_{2}+\mathrm{H}_{2} \mathrm{O} \rightarrow \\
2 \mathrm{CH}_{3} \mathrm{COO}^{-}+\mathrm{H}^{+}+1 / 2 \mathrm{CH}_{4}\end{array}$ & $-17 \cdot 1$ & & \\
\hline $\mathrm{G}(4 \mathrm{~A}+3 \mathrm{C})$ & $4 \mathrm{CH}_{3} \mathrm{CH}_{2} \mathrm{COO}^{-}+2 \mathrm{H}_{2} \mathrm{O} \rightarrow 4 \mathrm{CH}_{3} \mathrm{COO}^{-}+\mathrm{CO}_{2}+3 \mathrm{CH}_{4}$ & $-105 \cdot 6$ & & \\
\hline $\mathrm{H}(\mathrm{A}+\mathrm{D})$ & $2 \mathrm{CH}_{3} \mathrm{CH}_{2} \mathrm{COO}^{-} \rightarrow \mathrm{CH}_{3} \mathrm{COO}^{-}+\mathrm{CH}_{3} \mathrm{CH}_{2} \mathrm{CH}_{2} \mathrm{COO}^{-}$ & $0 \cdot 12$ & & \\
\hline $\mathrm{I}(3 \mathrm{~F}+\mathrm{A})$ & $4 \mathrm{CH}_{3} \mathrm{CH}_{2} \mathrm{COO}^{-}+2 \mathrm{CO}_{2}+2 \mathrm{H}_{2} \mathrm{O} \rightarrow 7 \mathrm{CH}_{3} \mathrm{COO}^{-}+3 \mathrm{H}^{+}$ & 1.91 & & \\
\hline
\end{tabular}

$* \mathrm{H}_{2}$ activity for $\Delta G=0$ with the following activities: $\mathrm{CH}_{4}, 0.5 \mathrm{~atm} ; \mathrm{CO}_{2}, 0.5 \mathrm{~atm}$; acetate, propionate and butyrate at $1 \mathrm{mM}$; $\mathrm{pH}=7$.

$\uparrow \mathrm{H}_{2}, \mathrm{CO}_{2}$, and $\mathrm{CH}_{4}$ in the gaseous state; $\mathrm{H}^{+}$at $10^{-7} \mathrm{~mol}$ activity per $\mathrm{kg}$; all other substances in aqueous solution at $1 \mathrm{~mol}$ of activity per $\mathrm{kg} ; 25^{\circ} \mathrm{C}$ (Thauer et al., 1977).

enrichment cultures could also grow in the absence of syntrophic interactions by fermenting fumarate to succinate and $\mathrm{CO}_{2}$, and demonstrated the enzymes of a fermentative pathway that includes acetyl-CoA oxidation to $\mathrm{CO}_{2}$ (Plugge et al., 1993). They were unable to grow Syntrophobacter wolinii axenically on fumarate because fumarate was metabolized by the sulfate-reducing bacterium present in that syntrophic culture (Stams et al., 1993). In this paper, we report the isolation of the type strain of Syntrophobacter wolinii from its co-culture with Desulfovibrio strain G11 in monoxenic co-culture with Methanospirillum hungateii and in axenic culture with fumarate as a catabolic substrate.

Propionate degradation by Syntrophobacter wolinii (Houwen et al., 1991), anaerobic sediments (Schink, 1985), anaerobic digestors (Robbins, 1987, 1988; Tholozan et al., 1988) and other methanogenic environments (Boone, 1984; Houwen et al., 1987, 1990; Koch et al., 1983) occurs mainly by the methyl-malonyl pathway, with succinate as a symmetrical intermediate. This pathway leads to the production of 1 mol acetate, $1 \mathrm{~mol} \mathrm{CO}$ and three pairs of electrons (i.e. a total of $3 \mathrm{~mol} \mathrm{H}_{2}$ and formate) per mol propionate degraded (Table 1, equation A). However, some propionate in anaerobic digestors is reductively carboxylated to butyrate (Samain et al., 1984; Tholozan et al., 1988), and this reduction can occur in the absence of methanogenesis (Samain et al., 1984). This six-electron reduction (e.g. Table 1, equation D) probably does not use $\mathrm{H}_{2}$ as electron donor if it is a catabolic reaction, because the reaction is not exergonic at the low $\mathrm{H}_{2}$ concentrations found in anaerobic digestors. However, the electrons to accomplish this reduction could be generated internally, such as by propionate oxidation (Table 1, equation $\mathrm{H}$ ) or, in part, by butyrate oxidation (Table 1 , equation D).

In this paper, we report the isolation of strain $L Y P^{\mathrm{T}}$, a bacterium that syntrophically degrades propionate with butyrate as a small but significant product, and that also slowly degrades butyrate. We propose it as the type strain of Smithella propionica gen. nov., sp. nov. This strain's 16S rDNA sequence, whose determination is reported herein, has been used to develop primers that detect phylogenetically similar organisms in anaerobic digestors (Sauer et al., 1997). Portions of this material were reported previously (Liu et al., 1998).

\section{METHODS}

Source of inoculum and cultures. The source from which strain $\mathrm{LYP}^{\mathrm{T}}$ was enriched was an up-flow anaerobic filter inoculated with digested domestic sewage sludge and operated with propionate as the major feedstock for 6 months. Cultures were obtained from the Oregon Collection of Methanogens (OCM): Syntrophobacter wolinii $\mathrm{DB}^{\mathrm{T}}$ in coculture with Desulfovibrio G11 (= OCM 467), Syntrophomonas wolfeii LYB (= OCM 65), which is a butyrateoxidizing syntroph (Boone et al., 1989). Methanosarcina barkeri NIH-1 (= OCM 266) was purified from Methanosarcina barkeri NIH (= OCM 265) (Blaylock \& Stadtman, 1966) by roll-tube isolation in MS medium with $50 \mathrm{mM}$ methanol. Methanospirillum hungateii $\mathrm{JF}-1^{\mathrm{T}}\left(=\mathrm{OCM} 16^{\mathrm{T}}\right)$ is a $\mathrm{H}_{2}$ - and formate-utilizing methanogen.

Media and culture technique. We used the anaerobic techniques of Hungate (1969) with some modifications (Miller \& Wolin, 1974; Sowers \& Noll, 1995). Except where noted, we used MS medium (Boone et al., 1989), an 
anaerobic bicarbonate-buffered medium with $2 \mathrm{~g}^{-1}$ each of Trypticase peptone and yeast extract; $\operatorname{MES}\left(0 \cdot 5 \mathrm{~g} \mathrm{l}^{-1}\right)$ and $\mathrm{Na}_{2} \mathrm{~S} .9 \mathrm{H}_{2} \mathrm{O}\left(0 \cdot 25 \mathrm{~g}^{-1}\right)$ were the reducing agents. MS enrichment medium was the same as MS medium except that yeast extract and Trypticase peptone were reduced to $0.5 \mathrm{~g}$ of each per litre. We also used MS low-nutrient medium in which the amount of yeast extract was reduced to $0.01 \mathrm{~g} \mathrm{l}^{-1}$ and Trypticase peptone was omitted. Agar media contained $18 \mathrm{~g}$ purified agar $\mathrm{l}^{-1}$. For isolations, we placed cultures into anaerobic jars with an anoxic gas to eliminate oxygen diffusion through the stoppers, thus allowing longer anoxic incubations.

Analytical techniques. Methane was quantified by GC with flame-ionization detection (Maestrojuán \& Boone, 1991) and fatty acids by GC of free acids. Samples were acidified by adding $0.1 \mathrm{ml} 3 \mathrm{M}$ phosphoric acid to $0.9 \mathrm{ml}$ of sample. Injection volume was $1 \mu \mathrm{l}$. Acids were separated in a column ( $2 \mathrm{~m}$ long, with $2 \mathrm{~mm}$ i.d.) containing $10 \%$ (w/w) SP-1000 coated on Chromosorb 101. The column temperature was $105^{\circ} \mathrm{C}$ and carrier-gas $\left(\mathrm{N}_{2}\right)$ flow rate was $40 \mathrm{ml} \mathrm{min}{ }^{-1}$. Detection was by flame ionization. Concentrations were estimated by comparison of integrated peaks to those of standards.

Analysis of growth and purity. Growth of methanogenic cocultures was checked by methane measurement (Maestrojuán \& Boone, 1991), and growth of non-methanogenic cultures was monitored by optical density at $670 \mathrm{~nm}$ (Spectronic 21 ; Milton Roy). Purity was checked routinely by inoculating fluid thioglycollate medium (Difco) and MS medium. Immediately following the initial isolation of axenic cultures, media with $\mathrm{H}_{2}$ plus sulfate or $\mathrm{H}_{2}$ plus $\mathrm{CO}_{2}$ were also inoculated to check for the presence of sulfate-reducers or methanogens, as indicated. After 3-8 weeks incubation, these contamination-check cultures were visually checked for turbidity and microscopically checked for the presence of bacteria (Boone \& Bryant, 1980).

Electron microscopy. Cells were centrifuged from the growth medium and resuspended in $2.5 \%$ glutaraldehyde in $0.2 \mathrm{M}$ sodium cacodylate buffer $(\mathrm{pH} 7 \cdot 2)$ at room temperature and fixed for $30 \mathrm{~min}$. After two buffer washes, cells were fixed in $1 \%$ osmium tetroxide in the same buffer for $1 \mathrm{~h}$ at $4{ }^{\circ} \mathrm{C}$, washed in distilled water, dehydrated in an ethanol series, and embedded in low-viscosity epoxy resin for sectioning. Sections on Formvar-coated grids were poststained with uranyl acetate and lead citrate, and viewed and photographed with a Zeiss EM-10CA transmission electron microscope.

Cytochemical stain for poly-hydroxyalkanoate. Cells were stained for detection of poly- $\beta$-hydroxyalkanoate (Doetsch, 1981). A heat-fixed film of cells was stained with $0.3 \%$ Sudan black $\mathrm{B}$ in ethylene glycol for $15 \mathrm{~min}$, rinsed in toluene, counter-stained briefly with $0.5 \%$ aqueous safranin, and dried. Stained cells were examined without a coverslip with an oil-immersion objective lens on a Nikon Optiphot II microscope using differential interference contrast optics.

Phylogenetic analysis. DNA from strain $\mathrm{LYP}^{\mathrm{T}}$ was isolated by the chloroform/isoamyl alcohol procedure (Johnson, 1981). Approximately $20 \mathrm{ng}$ DNA was used as a template for PCR amplification (Sambrook et al., 1989). The PCR amplification primers (Weisburg et al, , 1991) were fDI (5' AGAGTTTGATCCTGGCTCAG) and rP2 (5' ACGGCTACCTTGTTACGACTT). The PCR amplification products were sequenced with an Applied Biosystems model 373A DNA sequencer by using the Taq DyeDeoxy terminator cycle sequencing method according to the manufacturer's procedures (McBride et al., 1989). The following primers were used for sequencing: C (5' ACGGGCGGTGTGTAC) (Lane et al., 1985), corresponding to positions 1406-1392 in the 16S rDNA nucleotide sequence of Escherichia coli (Brosius et al., 1978); C-complement (5' GTACACACCGCCCGT; E. coli positions 1392-1406); H (5' ACACGAGCTGACGACAGCCA; positions 1075-1056); G (5' CCAGGGTATCTAATCCTGTT; positions 800-781); Gcomplement (5' AACAGGATTAGATACCCTGG; positions 781-800); A (5' GTATTACCGCGG[C/G]TGCTG; positions 536-519); P (5' CTGCTTCCTCCCGTAGGAG; positions 357-339); P-complement (5' CTACGGGAGGCAGCAG; positions 342-357); and $\mathrm{F}_{2} \mathrm{C}$ ( $5^{\prime}$ AGAGTTTGATC[A/C]TGGCTC; positions 8-25). The assembled $16 \mathrm{~S}$ rDNA sequences were hand-aligned with the equivalent $16 \mathrm{~S}$ rDNA or rRNA sequences of all closely related strains found in the GenBank database. The initial sets of prealigned eubacterial sequences were obtained from the Ribosomal Database Project (Larsen et al., 1993). Each set of aligned sequences was analysed for maximum-parsimony with the program PAUP (Phylogenetic Analysis Using Parsimony) (Swofford, 1993) to construct the most parsimonious phylogenetic tree based on $E$. coli positions 14-676. Only the phylogenetically informative sites were considered, and alignment gaps were retained in the analysis. A heuristic search was carried out first (with standard program defaults), after which a bootstrap analysis placed confidence limits on the branch points of the resulting phylogenetic trees. Consensus phylogenetic trees for each alignment set were produced by bootstrapping at the $>50 \%$ confidence limit, with 100 replications (Felsenstein, 1993). The phylogenetic position of strain $L Y P^{\mathrm{T}}$, inferred from its $16 \mathrm{~S}$ rDNA sequence, was compared to the positions of the most closely related organisms, with successive comparisons based on the analytical results of the previous alignment.

The aligned sequences were then analysed with parsimony and distance matrix methods. The parsimony analysis was performed with the program PAUP as described above. The distance matrix analysis was carried out by using the PHYLIP package of the microcomputer programs (Felsenstein, 1993). Distances were calculated by the method of Jukes \& Cantor (1969), after which phylogenetic distances were estimated with the FITCH option, which makes use of the FitchMargoliash criterion (Fitch \& Margoliash, 1967) and some related least-squares criteria.

\section{RESULTS}

\section{Isolation of strain LYP' in monoxenic co-culture}

MS enrichment medium with $20 \mathrm{mM}$ propionate was inoculated $(5 \%)$ with an anaerobic filter and incubated at $37^{\circ} \mathrm{C}$. A stable enrichment culture was developed from this culture by transferring $10 \%$ to fresh MS lownutrient medium with $20 \mathrm{mM}$ propionate. The culture was maintained by routine transfer after methane production ceased. After six such transfers, a culture in mid-exponential growth phase was serially diluted and inoculated into MS enrichment medium with $20 \mathrm{mM}$ propionate. Each culture was co-inoculated with Methanospirillum hungateii. These dilutions were also inoculated into solidified medium in roll tubes with lawns of Methanospirillum hungateii, and the liquid cultures and roll-tube cultures were incubated at $37^{\circ} \mathrm{C}$. 
Colonies in roll-tube media did not appear to contain propionate-degrading bacteria. However, after 8 weeks incubation, the liquid culture inoculated with $0.1 \mathrm{nl}$ of original culture had grown. It contained epifluorescent curved rods appearing to be Methanospirillum hungateii and shorter, thicker, non-fluorescent rods. The methane formed by the culture was much less than that formed by co-cultures of Syntrophobacter wolinii. We used dilutions of this culture to inoculate MS roll-tube media that contained $20 \mathrm{mM}$ propionate and a lawn of both $N_{\text {sethanospirillum }}$ hungateii and Methanosarcina barkeri. After 6 months incubation, a colony was picked and inoculated into MS medium with $20 \mathrm{mM}$ propionate. This culture contained short, non-epifluorescent rods that were slightly narrower than those of Syntrophobacter wolinii, as well as epifluorescent cells appearing to be Methanospirillum hungateii and Methanosarcina barkeri. No growth was detected when this co-culture was inoculated into MS medium without propionate or into fluid thioglycollate medium, indicating the $a b$ sence of contaminants able to grow in these media. The co-culture was deposited in the Oregon Collection of Methanogens as OCM 441.

\section{Axenic isolation of strain LYP' with crotonate}

The co-culture grew very slowly in liquid MS medium with $20 \mathrm{mM}$ butyrate ( 5 months to complete growth) or $20 \mathrm{mM}$ crotonate (6 months to complete growth). Subsequent transfers (10\% of culture volume) grew faster (4-8 weeks). A crotonate-grown culture after several transfers contained fewer methanogens. It was serially diluted and inoculated into MS medium with $20 \mathrm{mM}$ crotonate. The highest dilutions that grew were those that had been inoculated with $0 \cdot 1 \mathrm{nl}$ of the original culture. These were examined microscopically and found to contain only non-epifluorescent cells appearing to be the propionate-degrading bacterium. This culture was checked for contamination by inoculation of thioglycollate medium, MS medium and MS medium with $\mathrm{H}_{2}$ added (to detect methanogens). The culture was axenic. It was named strain $L Y P^{\mathrm{T}}$ and deposited in OCM as OCM $661^{\mathrm{T}}$. This culture grew in MS medium with crotonate, but it was unable to grow when yeast extract and peptones were omitted. Thus, the strain required one or more growth factors present in yeast extract or peptones.

\section{Isolation of Desulfovibrio-free cultures of Syntrophobacter wolinii}

The methods used to obtain methanogenic co-cultures of strain LYP ${ }^{\mathrm{T}}$ were successfully applied to Syntrophobacter wolinii. We grew cultures of the triculture of strain LYP ${ }^{\mathrm{T}}$, Desulfovibrio strain G11 and Methanospirillum hungateii (Boone \& Bryant, 1980) in MS mineral medium plus $20 \mathrm{mM}$ propionate. After six transfers, Methanospirillum hungateii and Syntrophobacter wolinii were dominant, with very few cells of Desulfovibrio strain G11 evident. We inoculated dilu- tions of this culture into MS medium with propionate as substrate, also adding $0.1 \mathrm{ml}$ of a culture of Methanospirillum hungateii to each tube. After 2 months incubation, cultures that had been inoculated with $1 \mathrm{nl}$ of original culture had grown. Cells of Desulfovibrio strain G11 appeared to be absent: they could not be found by microscopic examination of the culture, nor could they be found after incubation of the culture in MS medium with sulfate and $\mathrm{H}_{2}$. The culture appeared to contain only two morphological types, those of Methanospirillum hungateii and of Syntrophobacter wolinii. This co-culture was inoculated into roll-tube medium with propionate and lawns of both Methanospirillum hungateii and Methanosarcina barkeri. After 6 months incubation, light yellow colonies formed that comprised three morphological types, attributed to Methanospirillum hungateii, Methanosarcina barkeri and Syntrophobacter wolinii. No growth occurred when the culture was inoculated into fluid thioglycollate medium.

\section{Axenic isolation of Syntrophobacter wolinii on fumarate}

A methanogenic co-culture of Syntrophobacter wolinii $\mathrm{DB}^{\mathrm{T}}$ and Methanospirillum hungateii was obtained by serial dilution of the triculture that also contained Methanosarcina barkeri. This co-culture was grown for several transfers in MS medium with $20 \mathrm{mM}$ fumarate. Microscopic examination revealed reduced numbers of Methanospirillum hungateii, so the culture was serially diluted into MS medium with $20 \mathrm{mM}$ fumarate. After 8 weeks incubation, the highest dilution that grew had produced no methane. This culture contained a single morphological type appearing to be Syntrophobacter wolinii. Microscopic examination and contamination checks in thioglycollate medium, MS medium without additional substrates and MS medium with $\mathrm{H}_{2}$ indicated that this was an axenic culture of Syntrophobacter wolinii $\mathrm{DB}^{\mathrm{T}}$. This culture was deposited in OCM as OCM $587^{\mathrm{T}}$. It grew on malate, fumarate or pyruvate, but not on propionate. However, when co-inoculated with Methanospirillum hungateii into MS medium with $20 \mathrm{mM}$ propionate, the culture grew and formed methane in expected amounts.

\section{Morphology}

Strain LYP ${ }^{\mathrm{T}}$ cells were elongated, slightly sinuous rods $0.5 \mu \mathrm{m}$ in diameter and $4-5 \mu \mathrm{m}$ in length (Fig. 1a and c). Cells as long as $10 \mu \mathrm{m}$ were observed. Cells usually contained one to several electron-light globules. Staining with Sudan black indicated that these bodies were poly- $\beta$-hydroxyalkanoate (Fig. 1c). The cells stained Gram-negative, and the walls had a typical Gramnegative ultrastructure (Fig. 1b).

For comparison we examined Syntrophobacter wolinii and found important differences. Although the cells are approximately the same dimensions, and were also Gram-negative, the ends of Syntrophobacter wolinii 


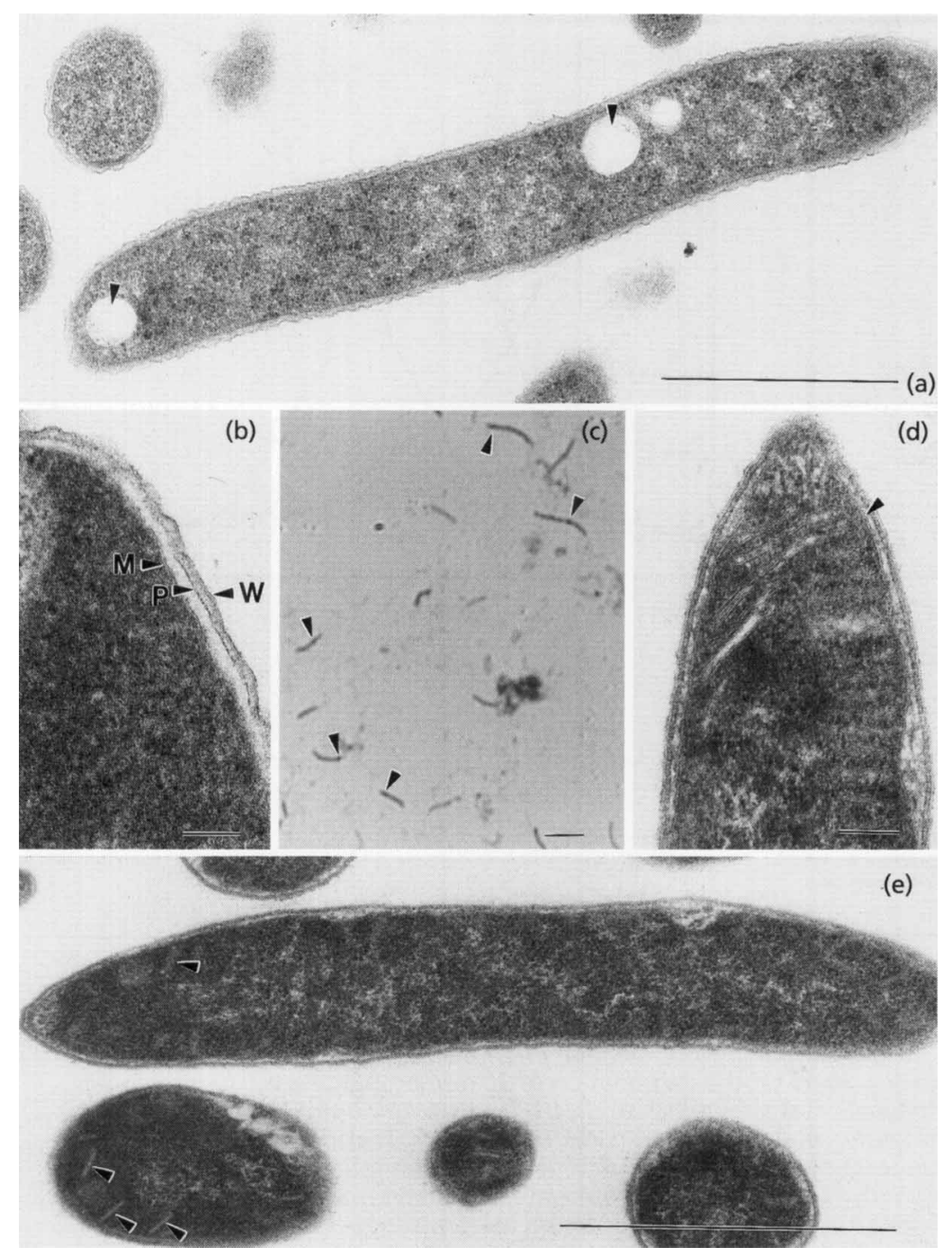

\begin{abstract}
Fig. 1. Micrographs of propionatedegrading bacteria: (a) Transmission electron micrograph of longitudinal section of Smithella propionica (arrowheads indicate granules of poly- $\beta$ hydroxyalkanoate within the cytoplasm; bar, $1 \mu \mathrm{m})$. (b) High magnification transmission electron micrograph thin-section of Smithella propionica, illustrating typical Gram-negative wall structure $(M$, plasma membrane; $P$, peptidoglycan; W, wall; bar, $0.1 \mu \mathrm{m}$ ). (c) Light microscopy of Sudan black $B$ cytochemical stain to demonstrate poly$\beta$-hydroxyalkanoate granules in cells of Smithella propionica (arrowheads indicate dark granules that are positively stained; bar, $5 \mu \mathrm{m})$. (d) High-magnification transmission electron micrograph thin-section of Syntrophobacter wolinii $\mathrm{DB}^{\mathrm{T}}$, illustrating typical Gram-negative wall structure and invaginations of plasma membrane (one at arrowhead) forming disk-like plates in cytoplasm (bar, $0.1 \mu \mathrm{m}$ ). (e) Transmission electron micrograph of a longitudinal section of Syntrophobacter wolinii $\mathrm{DB}^{\top}$; cells tapered to flat ends; arrowheads indicate several of the cytoplasmic disks as shown in part (d) (bar, $1 \mu \mathrm{m}$ ).
\end{abstract}

cells tapered to a blunt point (Fig. 1e). The cytoplasm of fumarate-grown cells contained numerous membrane-delimited inclusions (Fig. 1d and le), but these inclusions were absent in cells grown on pyruvate. The inclusions were invaginations of the plasma membrane (arrowhead, Fig. 1d) and in unusually thick sections appeared as disks when viewed face on. Gas vesicles as reported for Syntrophobacter pfennigii (Wallrabenstein et al., 1995b) were not found.

\section{Reconstitution of strain LYP' co-cultures from axenic cultures}

Like Syntrophomonas wolfeii, strain $\mathrm{LYP}^{\mathrm{T}}$ was able to grow axenically in MS medium with $20 \mathrm{mM}$ crotonate, but not with $20 \mathrm{mM}$ butyrate as catabolic substrate. However, when an axenic culture of strain $\mathrm{LYP}^{\mathrm{T}}$ was co-inoculated with Methanogenium strain PM or Methanospirillum hungateii, the co-cultures grew slowly on butyrate, and produced methane in expected quantities. Likewise, an axenic culture of strain $\mathrm{LYP}^{\mathrm{T}}$ did not grow in MS medium with $20 \mathrm{mM}$ propionate, but it grew in this medium when co-inoculated with
Methanospirillum hungateii and Methanosarcina barkeri. This triculture produced the stoichiometrically expected amount of methane from propionate (viz. $1.75 \mathrm{~mol}$ methane per mol propionate).

\section{Propionate degradation by co-cultures of strain LYP'}

When a reconstituted co-culture of strain $L Y P^{\mathrm{T}}$ and Methanospirillum hungateii was grown in $20 \mathrm{ml}$ MS medium with $0.4 \mathrm{mmol}$ propionate $(20 \mathrm{mM})$, only $0.06 \mathrm{mmol}$ methane was formed by $60 \mathrm{~d}$ incubation (Fig. 2a). This was much less than the expected amount of methane $(0.3 \mathrm{mmol})$ based on the degradation stoichiometry of Syntrophobacter wolinii (Table 1, equation $G$ ). In this time, the culture degraded $0 \cdot 3$ mmol propionate, and produced $0.4 \mathrm{mmol}$ acetate and $0.04 \mathrm{mmol}$ butyrate; about $0.1 \mathrm{mmol}$ propionate remained (Fig. 2a). This stoichiometry differed from that of Syntrophobacter wolinii (Boone \& Bryant, 1980), but was similar to that expected if $2 \mathrm{~mol}$ propionate were fermented to $1 \mathrm{~mol}$ each of butyrate and acetate (Table 1, equation $\mathrm{H}$ ), with most of the butyrate further degraded syntrophically (Table 1, equation F). 


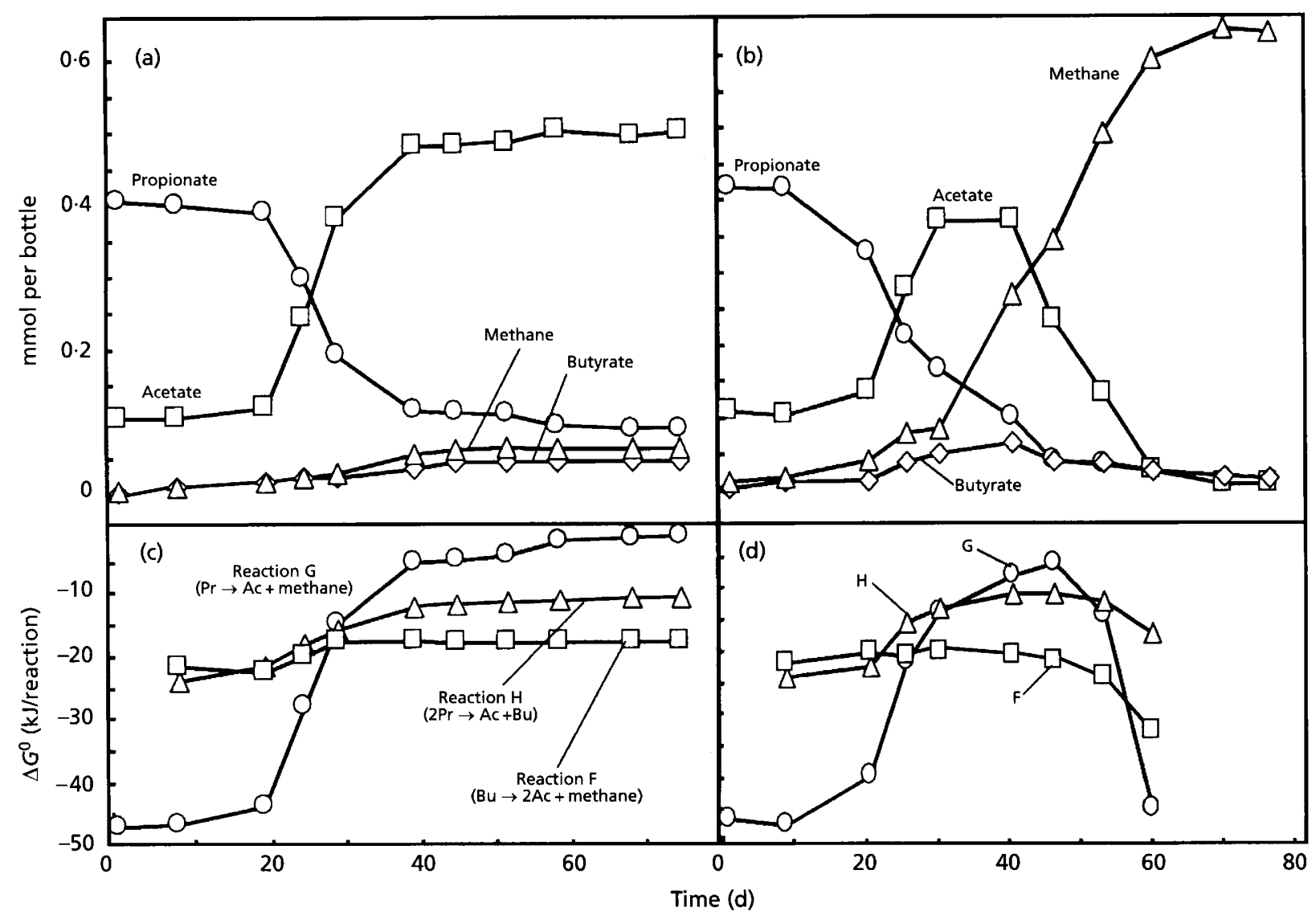

Fig. 2. Effect of acetate degraders and butyrate degraders on the degradation of $20 \mathrm{mM}$ propionate by the propionatedegrading strain LYP' and Methanospirillum hungateii. (a) Growth of strain LYP' plus Methanospirillum hungateii. (b) Growth of strain LYPT, Methanospirillum hungateii and Methanosarcina barkeri. (c) Thermodynamics of several propionate-degrading reactions at concentrations occurring during the batch growth shown in (a) (Reactions $G, H$ and $F$ refer to the reactions shown in Table 1). (d) Thermodynamics of several propionate-degrading reactions at concentrations occurring during the batch growth shown in (b) (Reactions $G, H$ and $F$ refer to the reactions shown in Table 1).

\section{Inhibition by $\mathrm{H}_{2}$ or formate}

To determine whether inefficient $\mathrm{H}_{2}$ (or formate) removal limited propionate oxidation by strain $L Y P^{\mathrm{T}}$, we increased the numbers of methanogens in the coculture. We did this by pre-growing Methanospirillum hungateii in $20 \mathrm{ml}$ medium with $\mathrm{H}_{2}$ added; we flushed out the gas space with $\mathrm{N}_{2}$ and $\mathrm{CO}_{2}(3: 7)$ after growth was complete. We then added $0.4 \mathrm{mmol}$ propionate $(20 \mathrm{mM})$ to this culture and inoculated it with the propionate-degrading co-culture. The increased numbers of methanogens had little effect on the fermentation (data not shown).

To confirm that strain $L Y P^{\mathrm{T}}$ required $\mathrm{H}_{2}$ and formate removal for propionate degradation, we added bromoethanesulfonate to inhibit the uptake of $\mathrm{H}_{2}$ and formate by the methanogen. When the co-culture was incubated with $0.5 \mathrm{mM}$ bromoethanesulfonate, methane was not produced, propionate concentration did not decrease, and no growth was detected. This finding is consistent with the inability of the Syntrophobacter wolinii to co-culture with Desulfovibrio strain G11 in the absence of sulfate (Boone \& Bryant, 1980), and with our finding that strain $L Y P^{T}$ did not grow axenically on propionate. However, it contrasts with experiments on sewage sludge, in which propionate conversion to butyrate continued in the presence of bromoethanesulfonate (Samain et al., 1984). Growth of strain $\mathrm{LYP}^{\mathrm{T}}$ on propionate depended on the removal of $\mathrm{H}_{2}$ and formate by Methanospirillum hungateii.

\section{Inhibition by acetate and other organic acids}

The incomplete degradation of propionate by the coculture (Fig. 2a) may have been due to inhibition by accumulating acetate. When the aceticlastic methanogen Methanosarcina barkeri was co-inoculated with the co-culture of strain LYP ${ }^{\mathrm{T}}$ and Methanospirillum hungateii, more propionate was degraded than when Methanosarcina barkeri was absent (Fig. 2b). Acetate accumulated and then disappeared; ultimately, much more methane was formed than in the absence of Methanosarcina barkeri. Thus, the high $(>20 \mathrm{mM})$ concentrations of acetate that had accumu- 


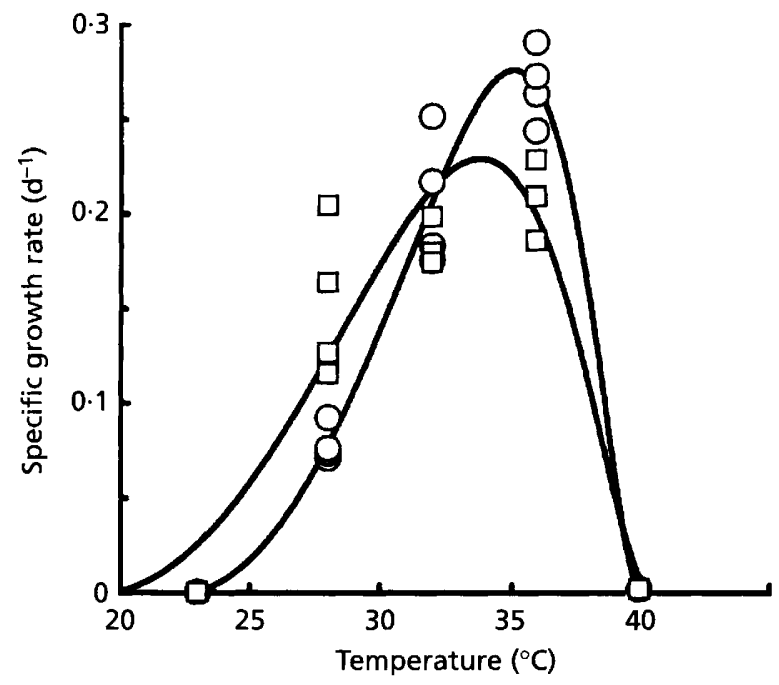

Fig. 3. Effect of temperature on growth rates of Smithella propionica $\mathrm{LYP}^{\top}(\square)$ and Syntrophobacter wolinii $\mathrm{DB}^{\top}(O)$.

lated in co-cultures of strain $\mathrm{LYP}^{\mathrm{T}}$ and Methanospirillum hungateii appeared to inhibit the extent of propionate degradation. Elevated acetate concentration also appeared to stimulate net butyrate formation, as more butyrate was formed when acetate was allowed to accumulate than when it was removed by Methanosarcina barkeri (Fig. 2).

Added acetate inhibited methanogenesis from propionate by strain $\mathrm{LYP}^{\mathrm{T}}$ and Methanospirillum hungateii. When such a co-culture was inoculated into medium with $20 \mathrm{mM}$ propionate and $10 \mathrm{mM}$ acetate, the acetate inhibited the rate (by $35 \%$ ) and extent (by $18 \%$ ) of methanogenesis from propionate compared to cultures without added acetate. When $20 \mathrm{mM}$ acetate was added, inhibition of the rate (by $66 \%$ ) and extent (by $49 \%$ ) of methanogenesis was more severe, and inhibition by $40 \mathrm{mM}$ added acetate was nearly complete.

To determine whether inhibition was a general feature of organic acids rather than product inhibition, we tested methanogenesis from propionate in the presence of various concentrations of added organic acid salts. Methanogenesis by the triculture of strain $\mathrm{LYP}^{\mathrm{T}}$, Methanospirillum hungateii and Methanosarcina barkeri was uninhibited by propionate concentrations as high as $60 \mathrm{mM}$, and good growth occurred even with $120 \mathrm{mM}$ propionate. Butyrate was not inhibitory at the highest concentrations tested $(20 \mathrm{mM})$, but rather it slightly stimulated methanogenesis. On the other hand, $10 \mathrm{mM}$ isobutyrate strongly inhibited methanogenesis from propionate.

\section{Other catabolic substrates}

Strain $\mathrm{LYP}^{\mathrm{T}}$ grew axenically on $10 \mathrm{mM}$ crotonate, producing approximately $1 \mathrm{~mol}$ acetate and $0.5 \mathrm{~mol}$ butyrate per mol crotonate. Added $\mathrm{H}_{2}$ inhibited growth on crotonate. Axenic cultures did not grow on butyrate, propionate, lactate, succinate, malate, fumarate, oxalate, isobutyrate, isovalerate, valerate, caproate, pyruvate or $\mathrm{H}_{2}$ plus $\mathrm{CO}_{2}$. We tested the ability of strain $\mathrm{LYP}^{\mathrm{T}}$ to grow syntrophically on these substrates by co-inoculating strain $L Y P^{T}$ together with Methanospirillum hungateii into media with $10 \mathrm{mM}$ of the test substrate. To determine whether the tested concentrations used were inhibitory, we also coinoculated media containing $10 \mathrm{mM}$ propionate plus $10 \mathrm{mM}$ of various other substrates. These co-cultures grew and produced methane from crotonate, butyrate, propionate, malate and fumarate, but not from lactate, succinate, oxalate, valerate, caproate or pyruvate. Ability to grow on isobutyrate could not be determined because $10 \mathrm{mM}$ isobutyrate was inhibitory.

\section{Effect of temperature and $\mathrm{pH}$ on growth}

Strain LYP ${ }^{\mathrm{T}}$ and Syntrophobacter wolinii were both mesophiles with similar growth rates (Fig. 3, Table 2). Both organisms grew fastest at $\mathrm{pH}$ values near neutral with a similar range (Fig. 4), but with slightly different minimum $\mathrm{pH}$ values: strain $\mathrm{LYP}^{\mathrm{T}}$ could not grow at $\mathrm{pH}$ values of 6.3 or below, whereas Syntrophobacter wolinii grew well at $\mathrm{pH} 6 \cdot 1$.

\section{Effect of salinity on growth}

Strain LYP ${ }^{\mathrm{T}}$ and Syntrophobacter wolinii also differed in their sensitivity to $\mathrm{NaCl}$. Each grew well in $\mathrm{MS}$ medium with $20 \mathrm{mM}$ of substrate added (total $\mathrm{Na}^{+}$ concentration $120 \mathrm{mM}$ ), but the growth rate of strain LYP $^{\mathrm{T}}$ was reduced by $50 \%$ when $86 \mathrm{mM} \mathrm{NaCl}$ was added, and growth was completely inhibited when $171 \mathrm{mM} \mathrm{NaCl}$ was added (Fig. 5). Syntrophobacter wolinii was completely inhibited in the presence of $86 \mathrm{mM} \mathrm{NaCl}$ or $\mathrm{KCl}$. However, it tolerated added sodium in MS medium with increased concentrations of sodium bicarbonate (Fig. 5), suggesting that it was particularly sensitive to chloride ion.

\section{Phylogeny}

The 16S rDNA sequence of strain LYPT was determined and compared with others in the Ribosomal Database Project (RDP) and GenBank (Table 2), and Fig. 6 shows a phylogenetic tree derived from these sequences. This figure shows that strain $\mathrm{LYP}^{\mathrm{T}}$ is most closely related $(99.4 \%$ sequence similarity) to strain Syn7, a non-axenic strain of propionate-degrading methanogenic culture whose sequence was determined in the laboratory of Alfons Stams. These two strains are most closely related to Syntrophus gentianae ( $88.9 \%$ sequence similarity) and Syntrophus buswellii $(87.8 \%)$, but these similarities were not sufficient to indicate that strain $\mathrm{LYP}^{\mathrm{T}}$ should be classified within the genus Syntrophobacter. Strain LYP ${ }^{\mathrm{T}}$ was even less related to Syntrophobacter, the genus of syntrophic propionate-degrading bacteria $(81 \cdot 1-83 \cdot 0 \%$ sequence similarity). 
Table 2. Sources of strains and 165 rRNA sequences

\begin{tabular}{|c|c|c|c|c|c|}
\hline Taxon & Strain name & $\begin{array}{l}\text { Culture } \\
\text { collection* }\end{array}$ & $\begin{array}{c}16 S \\
\text { rRNA } \\
\text { sequence }\end{array}$ & Database & Reference \\
\hline Bdellovibrio bacteriovorus & $109 \mathrm{~J} \dagger$ & DSM 3243 & M59297 & RDP & Unpublished \\
\hline Desulfobacter postgateii & $11070 \ddagger$ & DSM 684 & M26633 & RDP & Pfennig \& Biebl (1976) \\
\hline Desulfobacterium autotrophicum & HRM $2^{\mathrm{T}}$ & DSM $3382^{\mathrm{T}}$ & M34409 & RDP & Devereux et al. (1989) \\
\hline Desulfomonile tiedjeii & DCB- $1^{\mathrm{T}}$ & ATCC $49306^{\mathrm{T}}$ & M26635 & RDP & Unpublished \\
\hline Desulforhabdus amnigenus & $\mathrm{ASRB}^{\mathrm{T}}$ & DSM $10338^{T}$ & $\mathrm{X} 83274$ & GenBank & Oude Elferink et al. (1995) \\
\hline Desulfovibrio baarsii & Konstanz $^{\mathrm{T}}$ & DSM $2075^{\mathrm{T}}$ & M34403 & RDP & Devereux et al. (1989) \\
\hline Desulfovibrio desulfuricans & $\mathrm{MB}$ & ATCC 27774 & M34113 & RDP & Oyaizu \& Woese (1985) \\
\hline Desulfuromonas§ & & & M80618 & RDP & Amann et al. (1992) \\
\hline Desulfuromonas acetoxidans & Dangast $(2 \mathrm{ac} 9)^{\mathrm{T}}$ & DSM $2034^{\mathrm{T}}$ & M26634 & RDP & Widdel \& Pfennig (1981) \\
\hline Escherichia coli & $\mathrm{K}-12$ & & M29364 & RDP & Shen et al. (1982) \\
\hline 'Geobacter chapelleii' & & & U41561 & GenBank & Lonergan et al. (1996) \\
\hline 'Geobacter hydrogenophilus' & $\mathrm{H} 4$ & & U46860 & GenBank & Lonergan et al. (1996) \\
\hline 'Geobacter hydrogenophilus' & $\mathrm{H} 2$ & & U28173 & GenBank & Lonergan et al. (1996) \\
\hline Geobacter metallireducens & GS- $15^{\mathrm{T}}$ & OCM $645^{\mathrm{T}} \|$ & L07834 & GenBank & Lovley et al. (1993) \\
\hline Geobacter sulfurreducens & $\mathrm{PCA}^{\mathrm{T}}$ & & U13928 & GenBank & Caccavo et al. (1994) \\
\hline Pelobacter acetylenicus & WoAcy $1^{\mathrm{T}}$ & DSM $3246^{\mathrm{T}}$ & X70955 & RDP & Evers et al. (1993) \\
\hline Pelobacter propionicus & OttBd1 $1^{\mathrm{T}}$ & DSM $2379^{\mathrm{T}}$ & X70954 & RDP & Evers et al. (1993) \\
\hline Syntrophobacter sp. & МРОВ & & X82874 & GenBank & Harmsen et al. (1995) \\
\hline Syntrophobacter pfennigii & 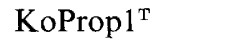 & DSM $10092^{\mathrm{T}}$ & $\mathrm{X} 82875$ & GenBank & Harmsen et al. (1995) \\
\hline Smithella propionica & LYP $^{\mathrm{T}}$ & OCM $661^{\mathrm{T}}$ & $\mathrm{X} 00000$ & GenBank & This paper \\
\hline Syntrophobacter wolinii & (Highly purified) & & X70906 & GenBank & Harmsen et al. (1993) \\
\hline Syntrophobacter wolinii & $\mathrm{DB}^{\mathrm{T}}$ & DSM $2805^{\mathrm{T}}$ & $\mathrm{X} 70905$ & RDP & Harmsen et al. (1993) \\
\hline Syntrophomonas wolfeii & Göttingen $^{\mathbf{T}}$ & OCM $41 \ddagger$ & M26492 & GenBank & Zhao et al. (1989) \\
\hline Syntrophus buswellii & $(\text { Unnamed })^{\mathrm{T}}$ & DSM $2612^{\mathrm{T}}$ & $\mathrm{X} 85131$ & GenBank & Wallrabenstein et al. (1995a) \\
\hline \multirow[t]{2}{*}{ Syntrophus gentianae } & HQGö1 $^{\mathrm{T}}$ & DSM $8423^{\mathrm{T}}$ & X85132 & GenBank & Wallrabenstein et al. (1995a) \\
\hline & Syn 7 & & $\mathrm{X} 87269$ & GenBank & H. J. M. Harmsen (unpublished) \\
\hline
\end{tabular}

* Culture collection indicated as the source of the culture for sequencing; ATCC, American Type Culture Collection; DSM, DSMZ

- Deutsche Sammlung von Mikroorganismen und Zellkulturen; OCM, Oregon Collection of Methanogens.

$\dagger$ The sequence obtained from RDP listed strain 109J as the source, but the GenBank entry for this sequence (M59297) lists the source as Bdellovibrio bacteriovorus, strain DSM 3243. However, DSM 3243, according to the DSMZ database, is Methanohalophilus portucalensis strain SF1. Our analysis of this sequence (Fig. 6) suggests that it is indeed that of Bdellovibrio bacteriovorus.

$¥$ The sequence obtained from RDP listed strain 2AC9 as the source, but the GenBank database indicates that sequence M26633 is Desulfobacter postgateii, strain DSM 684. DSMZ lists strain DSM 684 as the type strain of Desulfuromonas acetoxydans Pfennig and Biebl $1977^{\mathrm{AL}}$.

$\S$ The GenBank database indicates that sequence M80618 is the sequence of a Desulfuromonas-like organism, called 'population type 2 '. However, the submitters of that sequence, obtained from a methanogenic biofilm, indicate that 'population type 2 ' is related to Desulfovibrio vulgaris and 'population type 1' is related to Desulfuromonas acetoxidans (Amann et al., 1992). Our tree places this sequence closer to that of Desulfuromonas acetoxidans than to those of Desulfovibrio baarsii and Desulfovibrio desulfuricans, suggesting that sequence M80618 is actually 'population type 1' described by Amann et al. (1992).

\| No collection was indicated in the GenBank database, but the strain is available from this collection.

Evers et al. (1993) indicate this strain (WoAcy1) is DSM 2348, but the DSMZ database indicates that strain WoAcyl is DSM 3246.

\section{DISCUSSION}

The membranous inclusions found in fumarate-grown Syntrophobacter wolinii are reminiscent of those observed in fumarate-grown $E$. coli (Lemire et al., 1983; Weiner et al., 1984). These structure-function studies indicated that the rod-shaped inclusions in E. coli had $4 \mathrm{~nm}$ diameter globular projections of fumarate reductase resting on a short stalk and attached to a transmembrane tube-like basal piece. Since we found membrane-delimited inclusions in Syntrophobacter wolinii grown on fumarate but not in those grown on pyruvate, it is possible that these inclusions also were sites of fumarate reductase activity.

Syntrophobacter wolinii degrades propionate with a stoichiometry of $1 \mathrm{~mol}$ acetate formed per mol propionate degraded, whether this degradation is coupled syntrophically to sulfate reduction or to methanogenesis (Boone \& Bryant, 1980). This stoichiometry (Table 1, equation A) is consistent with the randomizing pathway that has been identified in this bacterium (Houwen et al., 1990). Although the amount of $\mathrm{H}_{2}$ or formate was not directly measured, its 


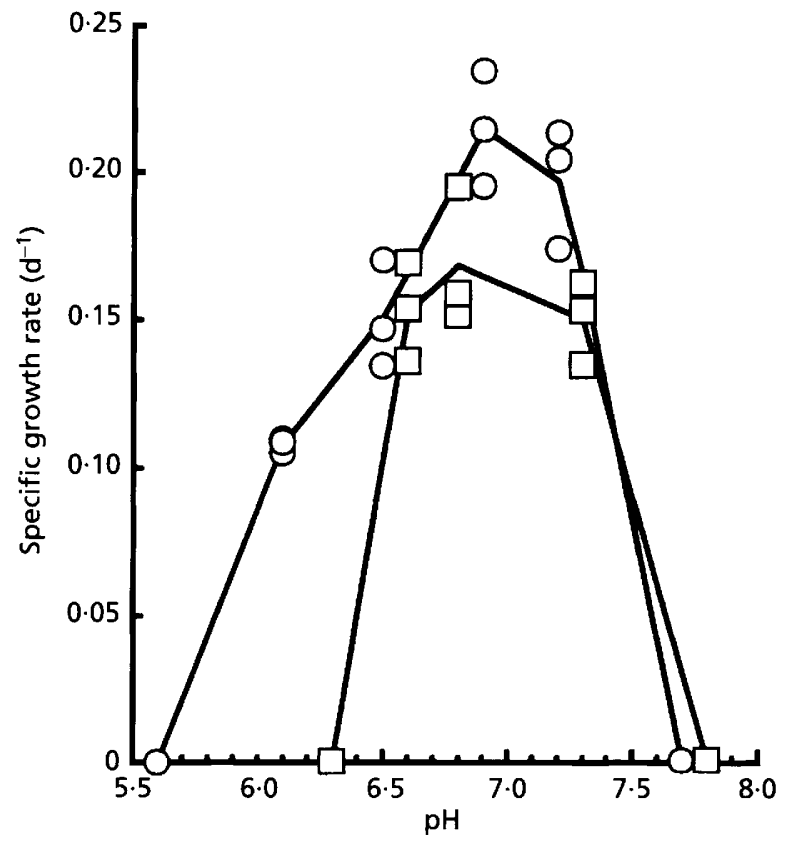

Fig. 4. Effect of $\mathrm{pH}$ on growth rates of Smithella propionica $\operatorname{LYP}^{\top}(\square)$ and Syntrophobacter wolinii $\mathrm{DB}^{\top}(\mathrm{O})$.

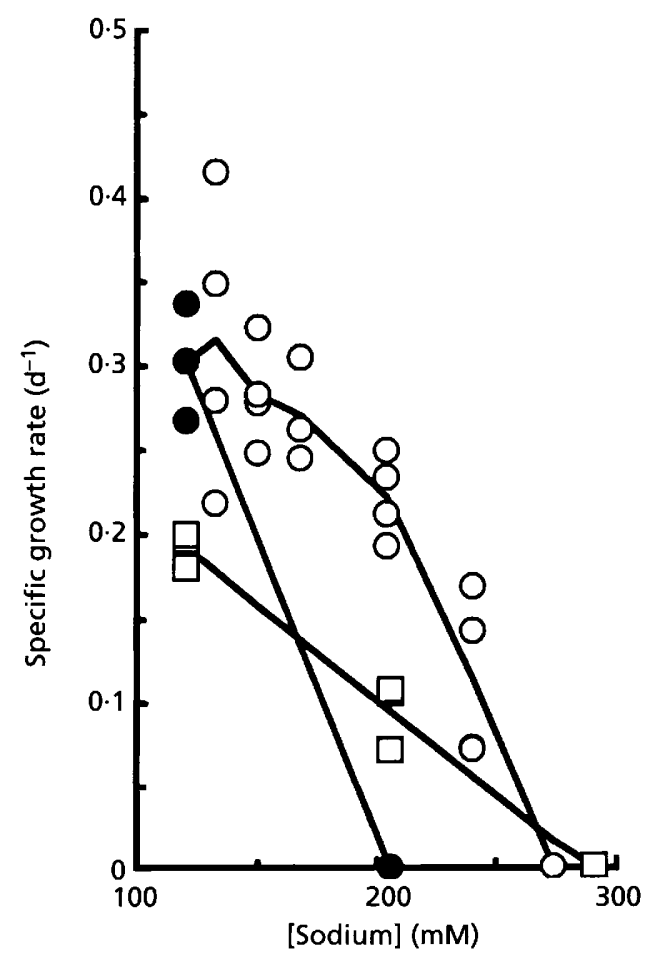

Fig. 5. Effect of added salts on growth rates of Smithella propionica LYP' and Syntrophobacter wolinii ${ }^{\top} B^{\top}$. Syntrophobacter wolinii with sodium chloride (O) or sodium bicarbonate (O) added to MS medium; Smithella propionica $\operatorname{LYP}^{\top}(\square)$. calculated value (calculated stoichiometrically from the ultimate product, $\mathrm{H}_{2} \mathrm{~S}$ or $\mathrm{CH}_{4}$ ) was near the expected amount. In contrast, strain $\mathrm{LYP}^{\mathrm{T}}$ in coculture with Methanospirillum hungateii formed much smaller amounts of methane and larger amounts of acetate during propionate degradation, with a stoichiometry closer to equations $\mathrm{F}+\mathrm{H}$ (Table 1 ). These deviations from expected stoichiometry could be explained by acetogenesis from $\mathrm{CO}_{2}$ and $\mathrm{H}_{2}$, but strain LYP ${ }^{T}$ was unable to grow on $\mathrm{H}_{2}$ plus $\mathrm{CO}_{2}$. Another possibility involves the reductive carboxylation of propionate to butyrate or butyryl-CoA, which has been documented in anaerobic digestors (Tholozan et al., 1988). This latter possibility is supported by the ability of strain $\mathrm{LYP}^{\mathrm{T}}$ to grow slowly on crotonate, and to grow in syntrophic co-culture on butyrate. These abilities indicate that it can couple energy to the $\beta$-oxidation of butyrate, as has been shown for Syntrophomonas wolfeii (McInerney et al., 1979, 1981; McInerney \& Wofford, 1992). This finding, together with the stoichiometry of its syntrophic degradation of propionate, is consistent with the dismutation of propionate to acetate and butyryl-CoA, followed by syntrophic $\beta$-oxidation of butyryl-CoA to acetate. The presence of a kinase or HS-CoA transferase of low activity would explain the release of small quantities of butyrate from butyryl-CoA, and this would also allow the observed slow growth of strain $\mathrm{LYP}^{\mathrm{T}}$ on butyrate (syntrophically) or on crotonate. This pathway is also consistent with the thermodynamics of these reactions, which were always negative during the batch growth of co-cultures (Fig. 2c).

The production of butyrate during syntrophic propionate degradation distinguished Smithella propionica from Syntrophobacter wolinii. We confirmed the previous finding (Boone \& Bryant, 1980) that Syntrophobacter wolinii also does not produce butyrate from propionate; the production of small amounts of butyrate might not have been detected in that study because the rumen-fluid medium used in the original study contained small amounts of butyrate.

\section{Taxonomy}

Our findings indicate that strain LYP ${ }^{\mathrm{T}}$ differs morphologically, physiologically and phylogenetically from previously described propionate-degrading bacteria. Strain $\mathrm{LYP}^{\mathrm{T}}$ is phylogenetically most similar to the genus Syntrophus, but the phylogenetic relationship is not sufficiently close to permit classification of strain $\mathrm{LYP}^{\mathrm{T}}$ in this genus. Also, the ability of strain LYP $^{\mathrm{T}}$ to grow on propionate separates it phenotypically from members of this genus. Therefore we propose a new genus and species, Smithella propionica gen. nov., sp. nov.

\section{Description of Smithella gen. nov.}

Smithella (Smi.thel'la. N.L. n. Smithella Smith, named after Paul H. Smith, for his early contributions to the 


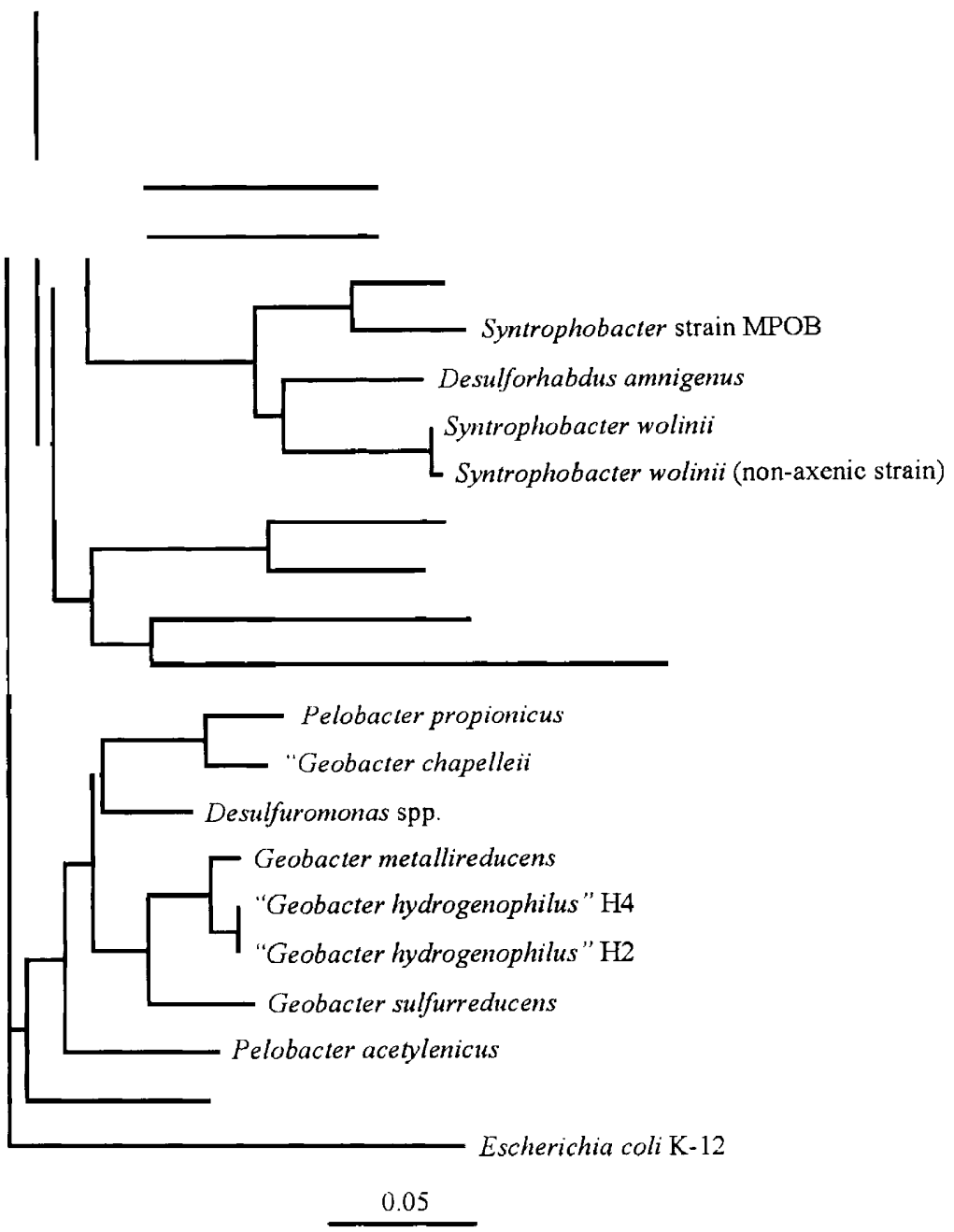

Fig. 6. Phylogenetic tree comparing Smithella propionica LYP' with other bacteria, based on a distance-matrix analysis of an approximately 683 base segment of the 16S rDNA and rRNA sequences. These data compared by parsimony and maximumlikelihood methods gave trees similar to this one. A partial tree is shown, in which $E$. coli was used as the outgroup. Bar, 5 base substitutions per 100 bases.

understanding of propionate degradation in methanogenic ecosystems).

Weakly motile Gram-negative rods. Strictly anaerobic. Mesophilic. Growth by syntrophic catabolism of propionate involving its reductive carboxylation to butyrate or butyryl-CoA. Habitat: methanogenic environments in which propionate is degraded. Type species: Smithella propionica.

Smithella propionica (pro.pi.o'ni.ca. M.L. n. acidum propionicum propionic acid; M.L. adj. propionica pertaining to propionic acid, on which the bacterium grows).

Gram-negative rods, $0.5 \mu \mathrm{m}$ in diameter, with most cells $3-5 \mu \mathrm{m}$ long, but some cells as long as $10 \mu \mathrm{m}$. Contain granules of poly- $\beta$-hydroxybutyrate. Weakly motile. Strictly anaerobic. Mesophilic. Fastest growth with $\mathrm{pH}$ near neutral and $\mathrm{Na}^{+}$and $\mathrm{Cl}^{-}$concentrations less than $100 \mathrm{mM}$. Grows syntrophically on propionate with $\mathrm{H}_{2}$ - or formate-using methanogenic partner. Grows slowly axenically by dismutating crotonate to butyrate and acetate. Habitat: methanogenic digestors. Type strain is strain $\mathrm{LYP}^{\mathrm{T}}\left(=\mathrm{OCM} 661^{\mathrm{T}}\right)$.

We thank Shuisong Ni (Washington State University, Richland) for helpful discussions, Donna S. Williams for help with the electron microscopy, and Sylvia E. Coleman for determining the presence of poly- $\beta$-hydroxyalkanoate granules. This work was supported by grant DE-FG0590ER61039 from the US Department of Energy through the Subsurface Science Program (Deep Microbiology Subprogram) and by a subcontract from master contract 206010 (to Pacific Northwest National Laboratory), task order 258705 . 


\section{REFERENCES}

Amann, R. I., Stromley, J., Devereux, R., Key, R. \& Stahl, D. A. (1992). Molecular and microscopic identification of sulfatereducing bacteria in multispecies biofilms. Appl Environ Microbiol 58, 614-623.

Blaylock, B. A. \& Stadtman, T. C. (1966). Methane biosynthesis by Methanosarcina barkeri; properties of the soluble enzyme system. Arch Biochem Biophys 116, 138-158.

Boone, D. R. (1982). Terminal reactions in the anaerobic digestion of animal waste. Appl Environ Microbiol 43, 57-64.

Boone, D. R. (1984). Propionate exchange reactions in methanogenic ecosystems. Appl Environ Microbiol 48, 863-864.

Boone, D. R. \& Bryant, M. P. (1980). Propionate-degrading bacterium, Syntrophobacter wolinii sp. nov. gen. nov., from methanogenic ecosystems. Appl Environ Microbiol 40, 626-632.

Boone, D. R., Johnson, R. L. \& Liu, Y. (1989). Diffusion of the interspecies electron carriers $\mathrm{H}_{2}$ and formate in methanogenic ecosystems and its implications in the measurement of $\mathrm{K}_{\mathrm{m}}$ for $\mathrm{H}_{2}$ or formate uptake. Appl Environ Microbiol 55, 1735-1741.

Brosius, J., Palmer, M. L., Kennedy, P. J. \& Noller, H. R. (1978). Complete nucleotide sequence of a 16S ribosomal RNA gene from Escherichia coli. Proc Natl Acad Sci USA 75, 4801-4805.

Caccavo, F., Jr, Lonergan, D. J., Lovley, D. R., Davis, M., Stolz, J. F. \& Mclnerney, M. J. (1994). Geobacter sulfurreducens sp. nov., a hydrogen- and acetate-oxidizing dissimilatory metal-reducing microorganism. Appl Environ Microbiol 60, 3752-3759.

Devereux, R., Delaney, M., Widdel, F. \& Stahl, D. A. (1989). Natural relationships among sulfate-reducing eubacteria. $J$ Bacteriol 171, 6689-6695.

Doetsch, R. N. (1981). Determinative methods of light microscopy. In Manual of Methods for General Bacteriology, pp. 21-33. Edited by P. Gerhardt, R. G. E. Murray, R. N. Costilow, E. W. Nester, W. A. Wood, N. R. Krieg \& G. B. Phillips. Washington, DC: American Society for Microbiology.

Evers, S., Weizenegger, M., Ludwig, W., Schink, B. \& Schleifer, K. H. (1993). The phylogenetic positions of Pelobacter acetylenicus and Pelobacter propionicus. Syst Appl Microbiol 16, 216-218.

Felsenstein, J. (1993). PHYLIP (Phylogeny Inference Package). Seattle, WA, USA.

Fitch, W. M. \& Margoliash, E. (1967). Construction of phylogenetic trees. Science 155, 279-284.

Harmsen, H. J. M., Wullings, B., Akkermans, A. D. L., Ludwig, W. \& Stams, A. J. M. (1993). Phylogenetic analysis of Syntrophobacter wolinii reveals a relationship with sulfate-reducing bacteria. Arch Microbiol 160, 238-240.

Harmsen, H. J. M., Kengen, H. M. P., Akkermans, A. D. L. \& Stams, A. J. M. (1995). Phylogenetic analysis of two syntrophic propionate-oxidizing bacteria in enrichments cultures. Syst Appl Microbiol 18, 67-73.

Houwen, F. P., Dijkema, C., Schoenmakers, C. H. H., Stams, A. J. M. \& Zehnder, A. J. B. (1987). ${ }^{13} \mathrm{C}-\mathrm{NMR}$ study of propionate degradation by a methanogenic coculture. FEMS Microbiol Lett 41, 269-274.

Houwen, F. P., Plokker, J., Stams, A. J. M. \& Zehnder, A. J. B. (1990). Enzymatic evidence for involvement of the methylmalonyl-CoA pathway in propionate oxidation by Syntrophobacter wolinii. Arch Microbiol 155, 52-55.

Houwen, F. P., Dijkema, C., Stams, A. J. M. \& Zehnder, A. J. B. (1991). Propionate metabolism in anaerobic bacteria: deter- mination of carboxylation reactions with ${ }^{13} \mathrm{C}-\mathrm{NMR}$ spectroscopy, Biochim Biophys Acta 1056, 126-132.

Hungate, R. E. (1969). A roll tube method for cultivation of strict anaerobes. Methods Microbiol 3B, 117-132

Johnson, J. L. (1981). Genetic characterization. In Manual of Methods for General Bacteriology, pp. 450-472. Edited by P. Gerhardt, R. G. E. Murray, R. N. Costilow, E. W. Nester, W. A. Wood, N. R. Krieg \& G. B. Phillips. Washington, DC: American Society for Microbiology.

Jukes, T. H. \& Cantor, C. R. (1969). Evolution of protein molecules. In Mammalian Protein Metabolism, vol. 3, pp. 21-132. Edited by H. N. Munro. New York: Academic Press.

Kaspar, H. F. \& Wuhrmann, K. (1978a). Kinetic parameters and relative turnovers of some important catabolic reactions in digesting sludge. Appl Environ Microbiol 36, 1-7.

Kaspar, H. F. \& Wuhrmann, K. (1978b). Product inhibition in sludge digestion. Microb Ecol 4, 241-248.

Koch, M., Dolfing, J., Wuhrmann, K. \& Zehnder, A. (1983). Pathways of propionate degradation by enriched methanogenic cocultures. Appl Environ Microbiol 45, 1411-1414.

Lane, D. J., Pace, B., Olsen, G. J., Stahl, D. A., Sogin, M. L. \& Pace, N. R. (1985). Rapid determination of $16 \mathrm{~S}$ ribosomal RNA sequences for phylogenetic analyses. Proc Natl Acad Sci USA 82, 6955-6959.

Larsen, N., Olsen, J. G., Maidak, B. L., McCaughey, M. J., Overbeek, R., Macke, T. J., Barsh, T. L. \& Woese, C. R. (1993). The ribosomal database project. Nucleic Acids Res 21, 3021-3023.

Lemire, B. D., Robinson, J. J., Bradley, R. D., Scraba, D. G. \& Weiner, J. H. (1983). Structure of fumarate reductase on the cytoplasmic membrane of Escherichia coli. J Bacteriol $\mathbf{1 5 5}$, 391-397.

Liu, Y., Balkwill, D. L., Aldrich, H. C. \& Boone, D. R. (1998). A novel anaerobic syntrophic bacterium that degrades propionate and produces butyrate. Atlanta, GA: Abstr Gen Meet Am Soc Microbiol, Abstract I-52, p. 316.

Lonergan, D. J., Jenter, H. L., Coates, J. D., Phillips, E. J., Schmidt, T. M. \& Lovley, D. R. (1996). Phylogenetic analysis of dissimilatory Fe(III)-reducing bacteria. $J$ Bacteriol 178, 2402 2408.

Lovley, D. R., Giovannoni, S. J., White, D. C., Champine, J. E., Phillips, E. J. P., Gorby, Y. A. \& Goodwin, S. (1993). Geobacter metallireducens gen. nov. sp. nov., a microorganism capable of coupling the complete oxidation of organic compounds to the reduction of iron and other metals. Arch Microbiol 159, 336-344.

McBride, L. J., Koepf, S. M., Gibbs, R. A., Salser, W., Mayrand, P. E., Hunkapiller, M. W. \& Kronick, M. N. (1989). Automated DNA sequencing methods involving polymerase chain reaction. Clin Chem 35, 2196-2201.

Mclnerney, M. J. \& Bryant, M. P. (1981). Review of methane fermentation fundamentals. In Fuel gas production from biomass, pp. 19-46. Edited by D. L. Wise. Boca Raton, FL: CRC Press.

Mclnerney, M. J. \& Wofford, N. Q. (1992). Enzymes involved in crotonate metabolism in Syntrophomonas wolfei. Arch Microbiol 158, 344-349.

Mclnerney, M. J., Bryant, M. P. \& Pfennig, N. (1979). Anaerobic bacterium that degrades fatty acids in syntrophic association with methanogens. Arch Microbiol 122, 129-135.

McInerney, M. J., Bryant, M. P., Hespell, R. B. \& Costerton, J. W. (1981). Syntrophomonas wolfei gen. nov. sp. nov., an anaerobic, 
syntrophic, fatty acid-oxidizing bacterium. Appl Environ Microbiol 41, 1029-1039.

Maestrojuán, G. M. \& Boone, D. R. (1991). Characterization of Methanosarcina barkeri $\mathrm{MS}^{\mathrm{T}}$ and 227 , Methanosarcina mazei S$6^{\mathrm{T}}$, and Methanosarcina vacuolata Z-761 ${ }^{\mathrm{T}}$. Int $J$ Syst Bacteriol 41, 267-274.

Miller, T. L. \& Wolin, M. J. (1974). A serum bottle modification of the Hungate technique for cultivating obligate anaerobes. Appl Microbiol 27, 985-987.

Oude Elferink, S. J. W. H., Maas, R. N., Harmsen, H. J. \& Stams, A. J. M. (1995). Desulforhabdus amigenus gen. nov., sp. nov., a sulfate reducer isolated from anaerobic granular sludge. Arch Microbiol 164, 119-124.

Oyaizu, H. \& Woese, C. R. (1985). Phylogenetic relationships among the sulfate respiring bacteria, myxobacteria, and purple bacteria. Syst Appl Microbiol 6, 257-263.

Pfennig, N. \& Biebl, H. (1976). Desulfuromonas acetoxidans gen. nov. and sp. nov., a new anaerobic, sulfur-reducing, acetateoxidizing bacterium. Arch Microbiol 110, 3-12.

Plugge, C. M., Dijkema, C. \& Stams, A. J. M. (1993). Acetyl-CoA cleavage pathway in a syntrophic propionate oxidizing bacterium growing on fumarate in the absence of methanogens. FEMS Microbiol Lett 110, 71-76.

Robbins, J. E. (1987). ${ }^{13} \mathrm{C}$ nuclear magnetic resonance studies of propionate catabolism in methanogenic cocultures. Appl Environ Microbiol 53, 2260-2261.

Robbins, J. (1988). A proposed pathway for catabolism of propionate in methanogenic cultures. Appl Environ Microbiol 54, 1300-1301.

Samain, E., Moletta, R., Dubourguier, H. C. \& Albagnac, G. (1984). Propionate conversion to butyrate in an anaerobic digester. In Biotechnological Advances in Processing Municipal Wastes for Fuels and Chemicals, pp. 223-233. Edited by A. A. Antonopoulos. Argonne, IL: Argonne National Laboratory.

Sambrook, J., Fritsch, E. F. \& Maniatis, T. (1989). Molecular Cloning : a Laboratory Manual, 2nd edn. Cold Spring Harbor, NY: Cold Spring Harbor Laboratory.

Sauer, K. D., Stroot, P., Mackie, R. I. \& Raskin, L. (1997). Microbial population dynamics linked to performance during anaerobic co-digestion of municipal solid waste and sewage sludge. In 8 th International Conference on Anaerobic Digestion. Sendai, Japan.

Schink, B. (1985). Mechanisms and kinetics of succinate and propionate degradation in anoxic freshwater sediments and sewage sludge. J Gen Microbiol 131, 643-650.

Schink, B. (1997). Energetics of syntrophic cooperation in methanogenic degradation. Microbiol Mol Biol Rev 61, 262-280.

Shen, W. F., Squires, C. L. \& Squires, C. L. (1982). Nucleotide sequence of the rrnG ribosomal RNA promoter region of Escherichia coli. Nucleic Acids Res 10, 3303-3313.

Sowers, K. R. \& Noll, K. M. (1995). Techniques for anaerobic growth. In Archaea : a Laboratory Manual, pp. 15-47. Edited by F. T. Robb, K. R. Sowers, H. J. Schreier, S. DasSarma \& E. M. Fleischmann. Cold Spring Harbor, NY: Cold Spring Harbor Laboratory.

Stadtman, T. C. \& Barker, H. A. (1951). Studies on the methane fermentation. VIII. Tracer experiments on fatty acid oxidation by methane bacteria. $J$ Bacteriol $\mathbf{6 1}, 67-80$.

Stams, A. J. M. \& Dong, X. (1995). Role of formate and hydrogen in the degradation of propionate and butyrate by defined suspended cocultures of acetogenic and methanogenic bacteria. Antonie Leeuwenhoek J Microbiol 68, 281-284.

Stams, A. J. M., Van Dijk, J. B., Dijkema, C. \& Plugge, C. M. (1993). Growth of syntrophic propionate-oxidizing bacteria with fumarate in the absence of methanogenic bacteria. Appl Environ Microbiol 59, 1114-1119.

Swofford, D. L. (1993). PAUP: Phylogenetic Analysis Using Parsimony. Champaign, IL: Illinois Natural History Survey.

Thauer, R. K., Jungermann, K. \& Decker, K. (1977). Energy conservation in chemotrophic anaerobic bacteria. Bacteriol Rev 41, $100-180$.

Thiele, J. H., Chartrain, M. \& Zeikus, J. (1988). Control of interspecies electron flow during anaerobic digestion: role of floc formation in syntrophic methanogenesis. Appl Environ Microbiol 54, 10-19.

Tholozan, J. L., Samain, E., Grivet, J. P., Moletta, R., Dubourguier, H. C. \& Albagnac, G. (1988). Reductive carboxylation of propionate to butyrate in methanogenic ecosystems. Appl Environ Microbiol 54, 441-445.

Wallrabenstein, C., Hauschild, E. \& Schink, B. (1994). Pure culture and cytological properties of Syntrophobacter wolinii. FEMS Microbiol Lett 123, 249-254.

Wallrabenstein, C., Gorny, N., Springer, N., Ludwig, W. \& Schink, B. (1995a). Pure culture of Syntrophus buswellii, definition of its phylogenetic status, and description of Syntrophus gentianae sp. nov. Syst Appl Microbiol 18, 62-66.

Wallrabenstein, C., Hauschild, E. \& Schink, B. (1995b). Syntrophobacter pfennigii sp. nov., a new syntrophically propionateoxidizing anaerobe growing in pure culture with propionate and sulfate. Arch Microbiol 164, 346-352.

Weiner, J. H., Lemire, B. D., Elmes, M. L., Bradley, R. D. \& Scraba, D. G. (1984). Overproduction of fumarate reductase in $E s$ cherichia coli induces a novel intracellular lipid-protein organelle. J Bacteriol 158, 590-596.

Weisburg, W. G., Barns, S. M., Pelletier, D. A. \& Lane, D. J. (1991). $16 \mathrm{~S}$ ribosomal DNA amplification for phylogenetic study. $J$ Bacteriol 173, 697-703.

Widdel, F. \& Pfennig, N. (1981). Studies on dissimilatory sulfatereducing bacteria that decompose fatty acids. I. Isolation of new sulfate-reducing bacteria enriched with acetate from saline environments. Description of Desulfobacter postgatei gen. nov., sp. nov. Arch Microbiol 129, 395-400.

Wolin, M. J. (1982). Hydrogen transfer in microbial communities. In Microbial Interactions and Communities, pp. 323-356. Edited by A. T. Bull \& J. H. Slater. London: Academic Press.

Zhao, H., Yang, D., Woese, C. R. \& Bryant, M. P. (1989). Assignment of Clostridium bryantii to Syntrophospora bryantii gen. nov., comb. nov. on the basis of $16 \mathrm{~S}$ rRNA sequence analysis of its crotonate-grown pure culture. Int $J$ Syst Bacteriol 40, 40-44. 